\title{
A Single-centre, Retrospective, Observational Analysis of Fulvestrant for Recurrent/metastatic Breast Cancer According to Metastatic Site
}

\author{
HIROMI OZAWA, ATSUSHI SATA, REIKO FUKUI, AYAKO BUN, TOMOKO HIGUCHI, \\ YUKIE FUJIMOTO, YOSHIMASA MIYAGAWA, MICHIKO IMAMURA and YASUO MIYOSHI \\ Department of Surgery, Division of Breast and Endocrine Surgery, \\ Hyogo College of Medicine, Nishinomiya, Japan
}

\begin{abstract}
Background/Aim: Factors influencing fulvestrant efficacy may be useful in selecting the optimal treatment regimen for postmenopausal Japanese women with metastatic/recurrent HR-positive, HER2-negative breast cancer. Patients and Methods: We retrospectively evaluated progression-free and overall survival (PFS and OS) in 100 fulvestrant-treated patients according to metastatic site. Results: Median PFS was significantly better in patients with non-visceral (bone and regional metastases; 22.8 months) vs. visceral metastasis (lung, liver, and other organs; 8.2 months; $p=0.024)$, although median OS did not differ ( $p=0.922)$. Median PFS in patients with lung metastasis (20.8 months) and non-visceral metastasis (22.8 months) were comparable; patients with liver metastasis (6.1 months) and other organ metastases (3.7 months) had worse prognoses. Conclusion: Patients with non-visceral metastases had a better prognosis than those with visceral metastases. Fulvestrant induced a longer PFS in patients with non-visceral metastasis, and also in those with lung metastasis without liver or other organ involvement.
\end{abstract}

Breast cancer remains one of the most frequently diagnosed cancers worldwide, and optimal treatment depends on several prognostic and predictive factors, including tumour stage and

This article is freely accessible online.

Data sharing statement: Data are unavailable because the Ethics Committee of the institute where the study was conducted does not permit the data of individual participants to be shared.

Correspondence to: Yasuo Miyoshi, Department of Surgery, Division of Breast and Endocrine Surgery, Hyogo College of Medicine, Mukogawa 1-1, Nishinomiya City, Hyogo 663-8501, Japan. Tel: +81 798456374, Fax: +81 798456252, e-mail: ymiyoshi@hyo-med.ac.jp

Key Words: Breast cancer, fulvestrant, metastasis, visceral, endocrine therapy. Trial registration: UMIN ID:000035772. localization, histology, patient age, and menopausal status (1). For patients who develop recurrent or metastatic hormone receptor (HR)-positive breast cancer, systemic treatments are recommended with the use of endocrine therapies such as aromatase inhibitors (AIs) and selective oestrogen receptor (ER) modulators preferred over more toxic chemotherapeutic regimens, unless chemotherapy is deemed necessary (e.g. for patients with visceral crisis) (1).

Fulvestrant is a selective ER degrader, which inhibits oestrogen signalling through the ER (2). It is indicated for the treatment of HR-positive, human epidermal growth factor receptor (HER)2-negative advanced breast cancer in postmenopausal women who have not previously received endocrine therapy, or in women with disease progression following endocrine therapy $(3,4)$. Data supporting the use of fulvestrant as first-line therapy in patients with metastatic breast cancer were provided by the phase 3 FALCON and phase 2 FIRST studies, in which fulvestrant treatment was compared with the AI anastrozole (5-7). In these clinical analyses, the efficacy endpoints of progression-free survival (PFS; FALCON) (5) and time to progression (TTP; FIRST) $(6,7)$ were prolonged with fulvestrant treatment compared with anastrozole, particularly in patients with non-visceral metastases. There is also clinical evidence to support the use of fulvestrant as secondor later-line therapy in patients who have progressed after initial endocrine therapy with an AI or anti-oestrogen. In the CONFIRM trial, patients receiving fulvestrant $500 \mathrm{mg}$ after relapse or progression with a previous endocrine therapy achieved a median PFS of 6.5 months, and $34 \%$ and $16 \%$ of patients remained alive and progression free after 12 and 24 months, respectively (8). This beneficial impact of fulvestrant was observed across all patient subgroups, with a non-significant trend towards improved PFS rates in patients with non-visceral metastases versus those with visceral metastases (8).

The indication for fulvestrant was recently updated to include its use in combination with palbociclib in women with disease progression after endocrine therapy (4). In the 
past four years, the cyclin-dependent kinase (CDK) 4/6 inhibitors palbociclib, ribociclib, and abemaciclib showed positive results in clinical trials (9-12) and received regulatory approval for use in the treatment of advanced or metastatic ER-positive breast cancer. The three CDK4/6 inhibitors have slightly different indications (13-17): in Japan, palbociclib and abemaciclib are approved in combination with an AI as first-line therapy, and in combination with fulvestrant after progression on prior endocrine therapy; ribociclib is approved in combination with an AI as first-line therapy, and in combination with fulvestrant as first-line or subsequent therapy. However, no consensus has been reached regarding the optimal treatment sequence of these new agents, and whether clinicians should use fulvestrant alone as first-line therapy, followed by a CDK 4/6 inhibitor in later lines, or whether CDK4/6 inhibitors should be used up front $(18,19)$. It would be helpful for clinicians to understand the factors which may impact fulvestrant efficacy in order to select the most appropriate drug for treatment.

It is known that breast cancer cells preferentially metastasize to specific organs (organotropic metastasis) (2022). However, reports of treatment efficacy and differences in outcome according to the metastatic organ are limited, and there is a data gap when it comes to considering treatment options in a clinical setting. In the FALCON and FIRST studies, there was a difference in the effect of fulvestrant when patients were divided into groups with visceral and non-visceral metastases (5-7). Thus, fulvestrant has been shown to be effective for non-visceral metastasis. There are also reports that patients with liver metastases have a poorer prognosis than patients with other metastases (23). However, it is unclear whether there is any difference in prognosis among patients with visceral metastases stratified by metastatic site, especially between lung metastasis and other metastases.

The objective of this study was to retrospectively investigate patients who received fulvestrant in real-world clinical practice in order to shed light on its clinical efficacy according to the site of metastasis and to expand the knowledge-base for clinicians when choosing a treatment regimen for their patients with recurrent or metastatic breast cancer.

\section{Patients and Methods}

Study design. This was a retrospective, single-centre, observational analysis of patients with metastatic or recurrent breast cancer who received fulvestrant treatment at the Hyogo College of Medicine (Hyogo, Japan) between November 2011 and May 2018 (Clinical trial registration: UMIN ID:000035772). For eligible patients, electronic medical records were reviewed to extract data on clinical characteristics, including age, tumour histology, receptor status, metastatic sites, and prior treatment. All procedures were in accordance with the ethical standards of the institutional research committee (Hyogo College of Medicine Institutional Review Board approval \#1969) and with the 1964 Helsinki declaration and its later amendments or comparable ethical standards. For this type of retrospective analysis, formal consent is not required.

Patients and treatment. Postmenopausal female patients with histologically diagnosed HR-positive breast cancer, stage 4 with metastasis, or recurrent breast cancer who received fulvestrant as firstline, second-line, or later therapy were eligible for inclusion. Patients with HER2-positive disease were eligible for inclusion if they had received fulvestrant monotherapy. Patients who received first-line fulvestrant therapy had received no prior hormone therapy for breast cancer (hormone therapy-naïve) or had cancer recurrence more than 12 months after completion of postoperative endocrine therapy. Patients who received second-line fulvestrant therapy had either developed progressive disease during first-line hormone therapy or had a recurrence within 12 months of postoperative hormone therapy. Patients who received third-line or later fulvestrant therapy had developed progressive disease during the previous therapy.

Exclusion criteria were patients with stage 1-3 disease who were treated with preoperative hormone therapy; patients with concomitant use of a luteinizing hormone-releasing hormone agonist, CDK4/6 inhibitor, or anti-HER2 therapy; patients who had participated in any other randomized controlled study; and patients in whom fulvestrant treatment was being re-administered after an earlier failure.

In each case, fulvestrant was administered according to the recommendations of the Japanese package insert (24). In brief, $500 \mathrm{mg}$ fulvestrant was administered intramuscularly (as two doses, one each into the left and right buttocks) at the first visit, after 2 weeks, after 4 weeks, and every 4 weeks thereafter.

Efficacy outcomes. The primary study endpoint was PFS. The secondary endpoint was overall survival (OS). PFS was defined as the time elapsed between fulvestrant treatment initiation and objective tumour progression or any death. OS was defined as the duration between the start of fulvestrant treatment until death from any cause. Responses were assessed using the Response Evaluation Criteria in Solid Tumours (RECIST) version 1.1.

PFS and OS were evaluated according to the organ of metastasis. Non-visceral metastasis was divided into bone and regional metastasis (regional lymph nodes and skin), and visceral metastasis into lung, liver, and other organs (brain, peritoneum, stomach, spleen, adrenal gland, and rectum).

Safety outcomes. Safety data and adverse events (AEs) were collected, based on the details provided in the medical records. AEs were classified according to Common Terminology Criteria for Adverse Events (CTCAE) version 4.0, severity grade, and whether they were considered to be causally related to fulvestrant treatment.

Statistical methods. No calculations were performed for sample size; all eligible patients who received fulvestrant treatment prior to the cut-off date were included in the analyses. Consecutive patient data were extracted from electronic medical records.

Categorical variables were described by frequency and proportion; summary statistics (median, range) were used to report continuous data. Survival curves were obtained using the KaplanMeier method based on the log-rank test. The correlation between 
patient clinicopathologic features and survival was evaluated using Fisher's exact test (for categorical variables), and the Wilcoxon rank-sum test (for quantitative variables). Univariate and multivariate regression analyses using Cox's proportional hazard model were performed to identify variables that were predictive of outcomes. Results were used to calculate hazard ratios (HRs), including $95 \%$ confidence intervals (CI). A two-sided $p$-value of $<0.05$ was considered statistically significant. Statistical analyses were performed using JMP Pro 13 software (SAS Institute Inc., Cary, NC, USA).

\section{Results}

Patients. Of 108 patients who received fulvestrant treatment between November 1, 2011 and May 31, 2018, data were obtained from 100 eligible patients who received fulvestrant monotherapy for recurrent, primary advanced or metastatic breast cancers as first- or later-line therapy at our institution.

Baseline patient characteristics are described in Table I and reveal that patients were representative of patients receiving endocrine therapy for recurrent breast cancer. At the data cut-off date of May 2018, 23 patients were still undergoing fulvestrant treatment, 58 had discontinued treatment owing to disease progression, one had died from non-breast cancer-related disease, and 18 had discontinued treatment for other reasons: AEs $(n=5)$; patient request $(n=3)$; alternative treatment regimen ( $\mathrm{n}=1$; radiotherapy); complete response continued $(n=1)$; and lost to follow-up $(n=8$; transferred to another hospital).

Efficacy outcomes. PFS and OS: Overall, the median PFS in patients who received fulvestrant was 17.0 months, and median OS was not reached. When evaluated by sites of metastasis, the median PFS was significantly better in patients with non-visceral metastasis (22.8 months) compared with those with visceral metastasis (8.2 months; $\mathrm{HR}=0.549 \quad[95 \% \mathrm{CI}=0.322-0.924] ; p=0.024$ ) (Figure 1a). However, there were no significant differences in median OS between patients with non-visceral and visceral metastases $(p=0.922)$ (Figure 1b).

Median PFS in patients with lung metastasis (20.8 months) was comparable with that in patients with bone/regional metastasis (22.8 months). However, the prognosis was poor in patients with liver metastasis (median PFS, 6.1 months) and other organ metastases (median PFS, 3.7 months) (Figure 2a). Median OS rates were comparable between sites of metastasis (Figure 2b). A marked difference in median PFS was also observed between patients with nonvisceral + lung metastases and those with visceral metastases (liver and other organs; $p=0.009$ ) (Figure 3a). However, median OS rates remained comparable between groups (Figure 3b). There were no statistically significant differences in PFS or OS according to the line of fulvestrant treatment (Figure $4 \mathrm{a}$ and $\mathrm{b}$ ).
Survival prognosis (univariate analysis) according to the site of metastasis: In univariate analyses of patient clinicopathologic characteristics and PFS, metastatic sites (visceral vs. non-visceral) and organs of metastasis (liver + others $v s$. non-visceral + lung) were found to be associated with worse outcomes (Table II). In contrast, univariate analyses of patient characteristics and OS did not show any differences in outcomes between these patient groups (Table III). Better PFS in patients with bone, regional, and lung metastases was consistently observed regardless of the baseline variable, with the exception of patients with Eastern Cooperative Oncology Group performance status 1 and 2 or Ki67 $\geq 20 \%$ (Figure 5).

Safety. Of the 100 patients included in the safety analysis, 47 did not report any AE, 26 reported at least one AE, and data were not available for the remaining 27 patients. The most frequently reported AEs were disorders at the injection site, all of which were Grade 1 in severity (induration, $n=12$; pruritis, $n=1$; maculopapular rash, $n=1$ ). Many of the cases of induration appeared to occur in patients who remained on treatment for extended periods of time ( $>1$ year). Eight patients reported myalgia, all Grade 1, and six patients reported malaise (four were Grade 1 and two were Grade 2). The remaining AEs occurred in one patient each and were liver function disorder (Grade 2), peripheral sensory neuropathy (Grade 1), hot flashes (Grade 1), and headache (Grade 1).

In total, four patients discontinued due to AEs: two patients with malaise (both Grade 2), one with liver function disorder (Grade 2), and one patient in whom the AE was unspecified (oral swelling). The two cases of malaise and the liver function disorder were thought to be treatment related, but the relationship to study drug was less clear for the patient with the unspecified $\mathrm{AE}$ (oral swelling) requiring treatment discontinuation. The changes in liver function occurred rapidly (within 2 weeks of initiating fulvestrant), while the remaining AEs leading to discontinuation occurred after several months or years of treatment. No new safety concerns associated with fulvestrant treatment were noted.

\section{Discussion}

This retrospective, observational analysis of 100 patients with metastatic breast cancer was designed to evaluate the clinical efficacy of fulvestrant according to the site of metastasis in real-world clinical practice. The study found that there were differences in clinical outcomes with fulvestrant treatment according to the site of metastasis. Median PFS was significantly better in patients with nonvisceral metastasis (22.8 months) compared with those with visceral metastasis ( 8.2 months; $p=0.024)$, although there were no significant differences in median OS between 


\section{a. PFS}

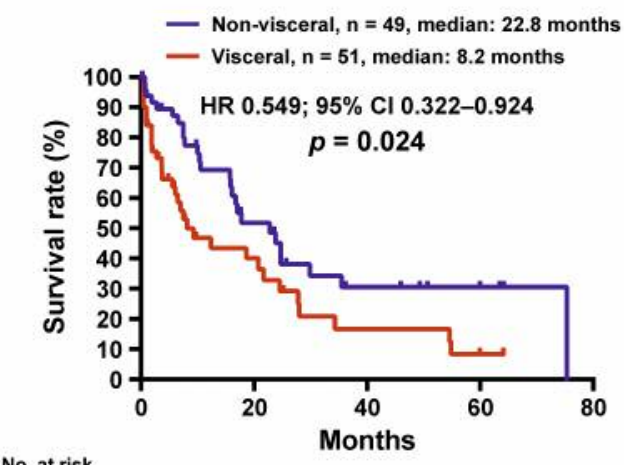

No. at risk

$\begin{array}{llllll}\text { Non-visceral } & 49 & 17 & 8 & 4 & 0 \\ \text { Visceral } & 51 & 11 & 5 & 2 & 0\end{array}$ b. os

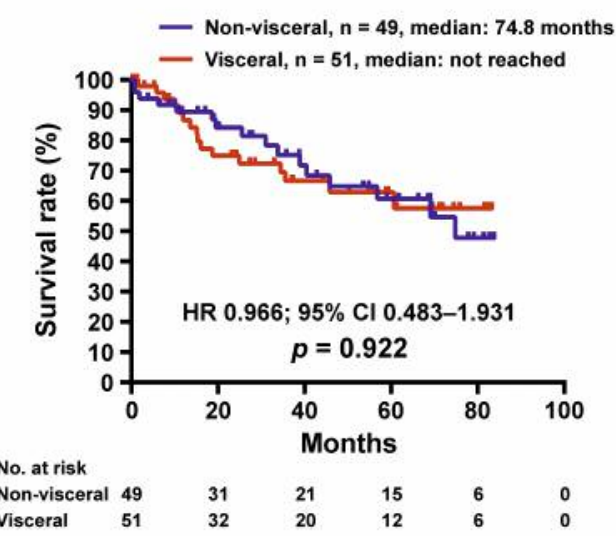

Figure 1. Survival according to the type of metastasis (visceral or non-visceral). (a) Progression-free survival (PFS). (b) Overall survival (OS). CI: Confidence interval; HR: hazard ratio.

\section{a. PFS}

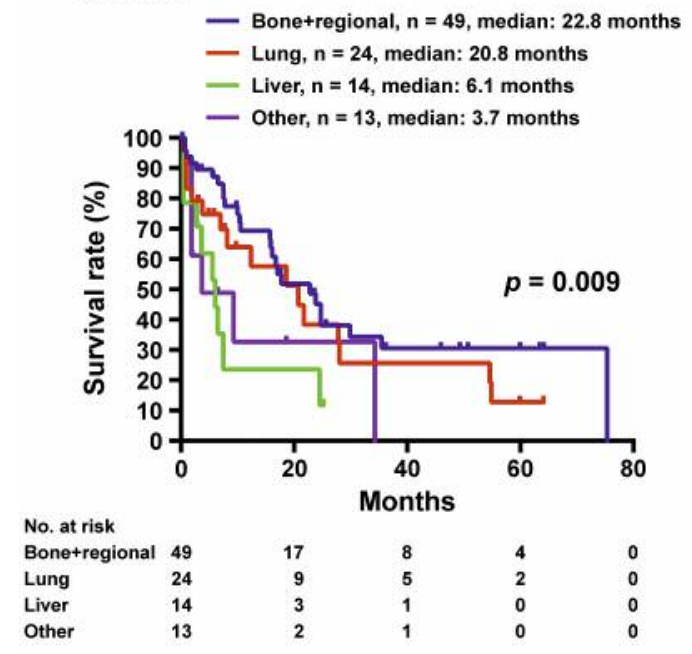

b. OS

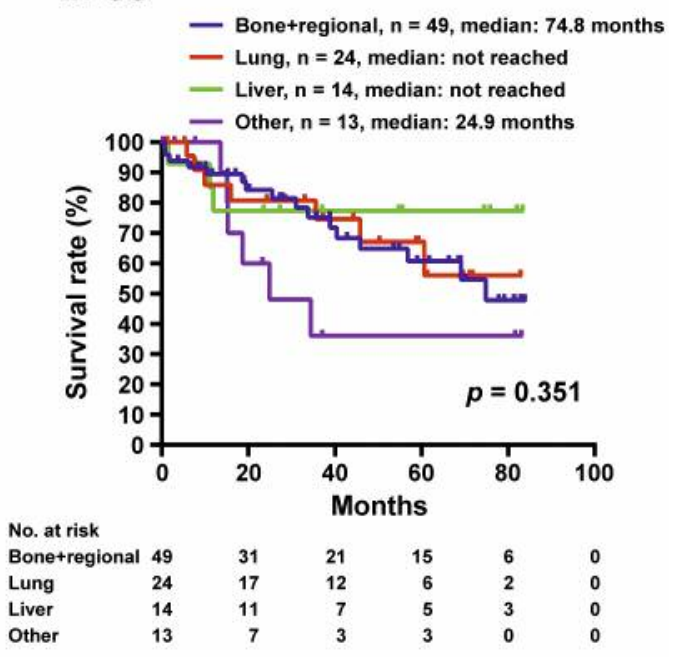

Figure 2. Survival according to the organ of metastasis (bone+regional, lung, liver, other). (a) Progression-free survival (PFS). (b) Overall survival (OS).

patients with non-visceral and visceral metastases $(p=0.922)$. Survival duration was longer when the metastasis site was lung compared with other visceral metastases. When the sites of metastasis were divided into non-visceral + lung and liver + other visceral sites, a better correlation with PFS was seen, compared with the division into visceral $v s$. non-visceral metastases. In univariate analyses, metastatic sites (visceral $v s$. non-visceral) and organs of metastasis (liver + others $v s$. non-visceral + lung) were found to be associated with worse outcomes.

A key finding from this analysis was that patients with lung metastasis had a better prognosis than those with liver or other visceral metastases. Although we cannot provide a definitive explanation for this result, there are several strands of evidence which allow us to speculate on the possible causes of this difference in outcomes. Based on the medical records of the patients in this analysis, there appeared to be no substantial difference between liver and lung metastases with regard to the time at which the metastasis was detected by screening. In four patients in whom metastasis was recorded in both lung and liver, the metastasis occurred first in bone in one patient, followed by lung, then liver, and in the other three patients, both lung and liver metastases were observed at the time of diagnosis. As such, the difference in prognosis is 


\section{a. PFS}

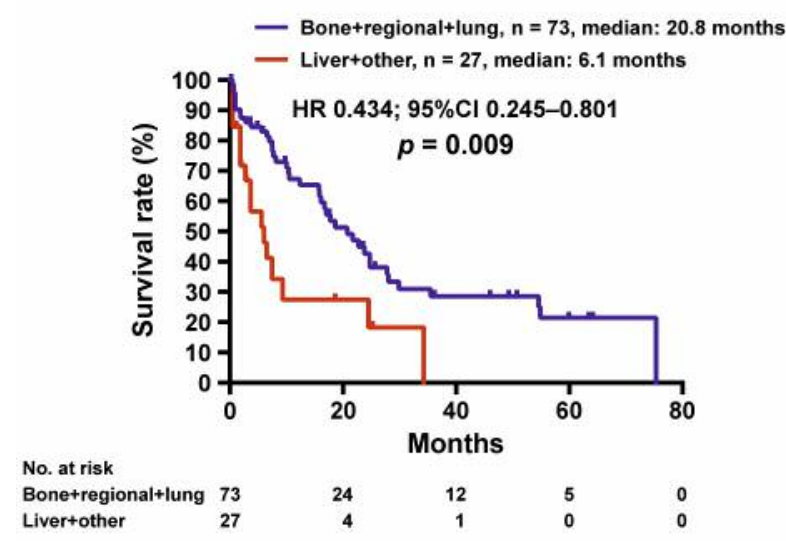

b. OS

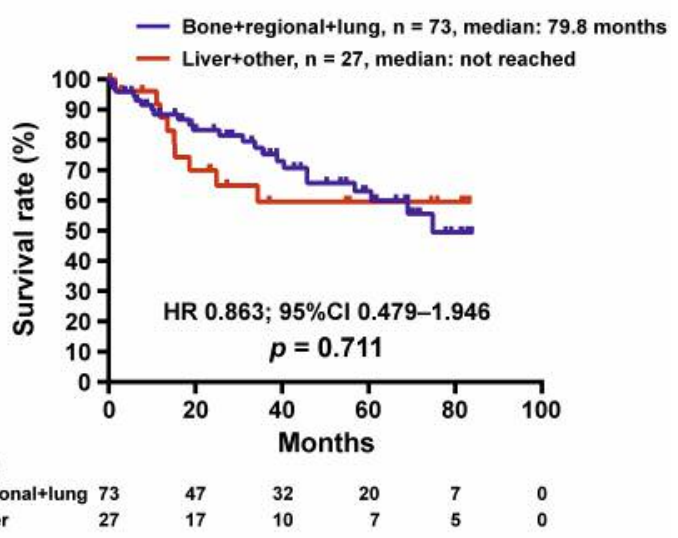

Figure 3. Survival according to type of metastasis (bone+regional +lung or liver+other). (a) Progression-free survival (PFS). (b) Overall survival (OS). CI: Confidence interval; HR: hazard ratio.

\section{a. PFS}

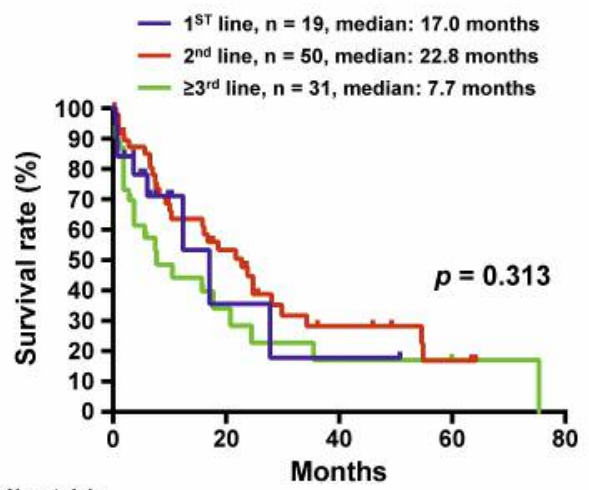

b. OS

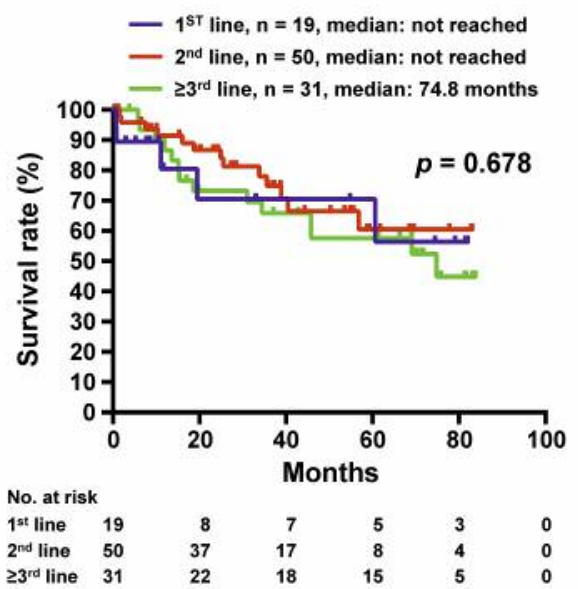

Figure 4. Survival according to fulvestrant line of therapy (first, second, or later). (a) Progression-free survival (PFS). (b) Overall survival (OS).

unlikely to be attributable to earlier detection. However, in breast cancer patients with visceral metastases, there appears to be a tendency for lung metastasis to occur prior to liver metastasis (25). This suggests that patients with liver metastasis are at a more advanced disease stage with generally worse health, which may partially explain the difference in outcomes between patients with these two kinds of metastasis In addition, activation of the growth factor pathway associated with resistance to endocrine therapy has also been reported in breast cancer patients with liver metastasis (21). Owing to high-grade malignancy, these patients may have a relatively poor prognosis. Finally, it is known that different types of breast cancer cells display metabolic heterogeneity according to the site of metastasis, with liver metastases, in particular, being more dependent on anaerobic glycolysis (26). This variability in metabolism may impact the relative aggressiveness of different metastases and their vulnerability to treatment, which in turn may explain the differences in sensitivity to fulvestrant therapy.

Of note, there was no significant difference in survival outcomes by fulvestrant treatment line. Patients who received fulvestrant as the second- or third-line treatment in clinical practice were responders to previous treatment with endocrine therapy and were in relatively good systemic condition. This may account for the small difference compared with first-line treatment. 


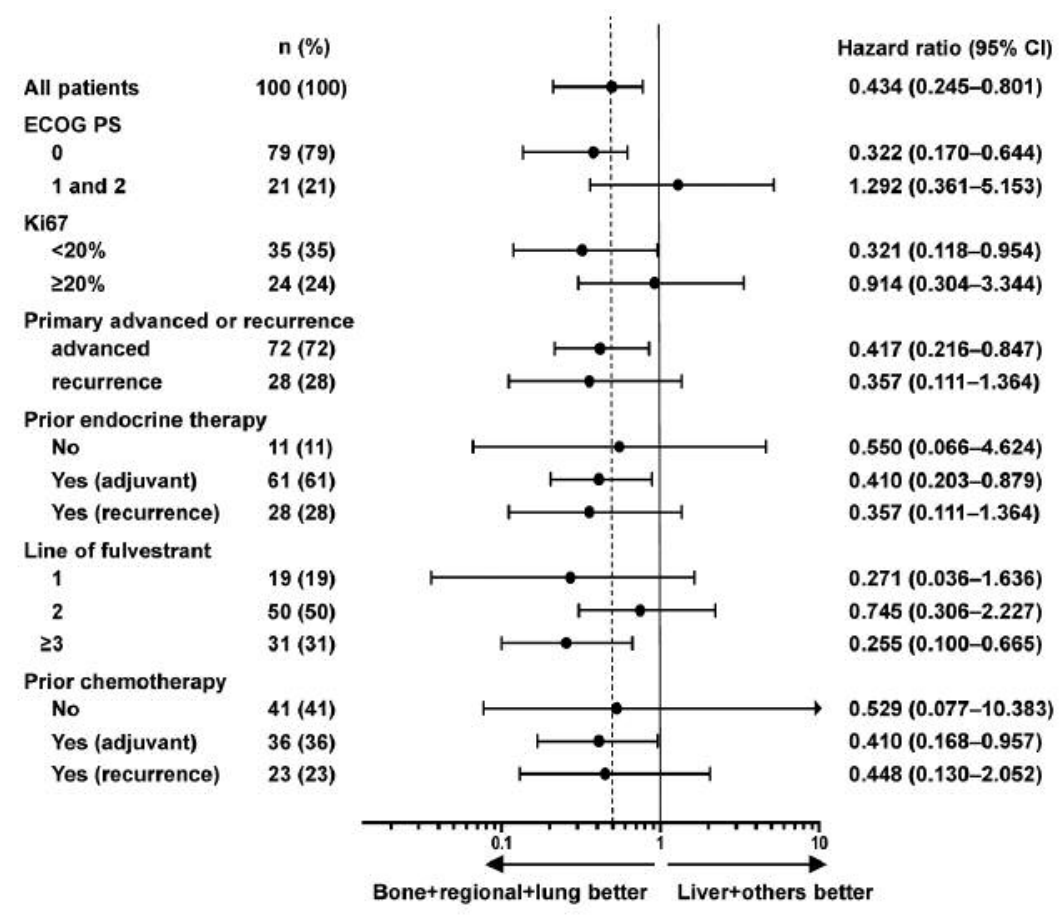

Figure 5. Subgroup analysis of progression-free survival among patients treated with fulvestrant according to the type of metastasis (bone+regional+lung or liver+others). CI: Confidence interval; ECOG PS: Eastern Cooperative Oncology Group performance status.

Overall, the findings of the current analysis support the hypothesis that the metastatic organ may be a useful indicator when predicting the efficacy of fulvestrant. Previously published clinical trials in which fulvestrant was used as the first-line treatment also reported a better prognosis in patients with non-visceral metastases. In the phase 3 FALCON study, fulvestrant significantly prolonged PFS compared with the AI anastrozole, particularly in patients with non-visceral disease; this benefit appeared to be driven by a longer duration of treatment response in fulvestrant-treated patients (5). In the phase 3 CONFIRM study, there was a trend towards improved PFS rates with fulvestrant treatment in patients with non-visceral metastases versus patients with visceral metastases, although the difference was not significant (8). However, there was no difference in OS regardless of visceral involvement at baseline (27). In the phase 2 FIRST study, in addition to an overall improvement in clinical outcomes with fulvestrant compared with anastrozole $(6,7)$, analysis of time to progression indicated that fulvestrant treatment provided greater benefit in patients without visceral involvement (28). A recent observational analysis also reported that among postmenopausal women with HR-positive, endocrinesensitive metastatic breast cancer, fulvestrant was associated with longer PFS in patients without baseline metastases at visceral sites (29). Patients with non-visceral metastases had a good prognosis in the current observational study; thus, the results reported in clinical trials have been confirmed in clinical practice.

The results of this analysis add to the evidence-base for fulvestrant treatment of breast cancer by evaluating efficacy in the context of individual metastatic sites to assess potential differences between specific organs. Fulvestrant demonstrated clinical benefit not only for bone/regional metastasis but also for lung metastasis. Our data confirm that prognoses are different between patients with lung metastases and those with other visceral metastases.

Overall, this article presents important and novel data on metastases by organ and, specifically, lung metastasis, which have not been available thus far. The prognosis according to metastatic site was identified in real-world patients who were found to be eligible for hormone therapy and received fulvestrant in clinical practice. Furthermore, the sample size of 100 patients is fairly large for a study in which fulvestrant was administered in clinical practice.

However, we acknowledge that the study also has limitations, several of which are inherent to retrospective analyses. This was an observational study, and the results were reliant on the completeness and accuracy of the medical records used. The patients included in the analysis, whilst representative of the general breast cancer population, were those judged capable of undergoing endocrine therapy. This 
Table I. Clinicopathological characteristics of patients treated with fulvestrant.

\begin{tabular}{|c|c|}
\hline Variable & $\begin{array}{c}\text { Patients } \\
\mathrm{N}=100\end{array}$ \\
\hline Age (years), median (range) & $66.9(44-91)$ \\
\hline \multicolumn{2}{|l|}{ ECOG PS } \\
\hline 0 & $79(79.0)$ \\
\hline 1 or 2 & $21(21.0)$ \\
\hline \multicolumn{2}{|l|}{ Histological type } \\
\hline IDC & $84(84.0)$ \\
\hline ILC & $5(5.0)$ \\
\hline Other & $3(3.0)$ \\
\hline Unknown & $8(8.0)$ \\
\hline \multicolumn{2}{|l|}{ Oestrogen receptor status } \\
\hline Positive & $94(94.0)$ \\
\hline Negative & $1(1.0)$ \\
\hline Unknown & $5(5.0)$ \\
\hline \multicolumn{2}{|l|}{ Progesterone receptor status } \\
\hline Positive & $77(77.0)$ \\
\hline Negative & $17(17.0)$ \\
\hline Unknown & $6(6.0)$ \\
\hline \multicolumn{2}{|l|}{ HER2 status } \\
\hline Positive $^{\mathrm{a}}$ & $5(5.0)$ \\
\hline Negative & $81(81.0)$ \\
\hline Unknown & $14(14.0)$ \\
\hline \multicolumn{2}{|l|}{ Ki67 } \\
\hline$<20$ (low) & $35(35.0)$ \\
\hline$\geq 20$ (high) & $24(24.0)$ \\
\hline Unknown & $41(41.0)$ \\
\hline \multicolumn{2}{|l|}{ Disease type } \\
\hline Primary advanced & $72(72.0)$ \\
\hline Recurrence & $28(28.0)$ \\
\hline \multicolumn{2}{|l|}{ Metastatic sites } \\
\hline Visceral & $51(51.0)$ \\
\hline Non-visceral & $49(49.0)$ \\
\hline \multicolumn{2}{|l|}{ Organ of metastasis } \\
\hline $\begin{array}{l}\text { Local and regional lymph node } \\
\text { without visceral metastasis }\end{array}$ & $14(14.0)$ \\
\hline Bone without visceral metastasis & $35(35.0)$ \\
\hline Lung without liver and other visceral ${ }^{\mathrm{b}}$ metastases & $24(24.0)$ \\
\hline Liver without other visceral metastases & $14(14.0)$ \\
\hline Other visceral metastases $\mathrm{b}$ & $13(13.0)$ \\
\hline \multicolumn{2}{|l|}{ Prior endocrine therapy } \\
\hline No & $11(11.0)$ \\
\hline Yes (adjuvant only) & $61(61.0)$ \\
\hline Yes (primary advanced or recurrent disease) & $28(28.0)$ \\
\hline \multicolumn{2}{|l|}{ Line of fulvestrant therapy } \\
\hline 1 & $19(19.0)$ \\
\hline 2 & $50(50.0)$ \\
\hline $3+$ & $31(31.0)$ \\
\hline \multicolumn{2}{|l|}{ Prior chemotherapy } \\
\hline No & $41(41.0)$ \\
\hline Yes (adjuvant only) & $36(36.0)$ \\
\hline Yes (primary advanced or recurrent disease) & $23(23.0)$ \\
\hline
\end{tabular}

Data are presented as $\mathrm{n}(\%)$ unless otherwise stated. ${ }^{\mathrm{a} A n t i-H E R} 2$ therapy was not used; bBrain and intra-abdominal. ECOG PS: Eastern Cooperative Oncology Group performance status; HER2, human epidermal growth factor receptor 2; IDC: invasive ductal carcinoma; ILC: invasive lobular carcinoma.
Table II. Univariate analysis of progression-free survival of patients treated with fulvestrant.

\begin{tabular}{|c|c|c|c|}
\hline Variable & $\begin{array}{c}\text { Number of } \\
\text { patients }\end{array}$ & $\begin{array}{c}\text { Hazard ratio } \\
(95 \% \mathrm{CI})\end{array}$ & $p$-Value \\
\hline \multicolumn{4}{|l|}{ ECOG PS } \\
\hline 0 & 79 & 1.000 & \\
\hline 1 or 2 & 21 & $1.440(0.680-2.766)$ & 0.321 \\
\hline \multicolumn{4}{|l|}{ Histologic type } \\
\hline IDC & 84 & 1.000 & \\
\hline ILC & 5 & $2.324(0.191-5.875)$ & 0.154 \\
\hline Other & 3 & $1.072(0.175-3.480)$ & 0.924 \\
\hline \multicolumn{4}{|c|}{ Progesterone receptor status } \\
\hline Positive & 77 & 1.000 & \\
\hline Negative & 17 & $0.652(0.351-1.304)$ & 0.214 \\
\hline \multicolumn{4}{|l|}{ HER 2 status by FISH } \\
\hline $3+$ or $2+$ & 5 & 1.000 & \\
\hline $1+$ or 0 & 81 & $0.987(0.301-6.067)$ & 0.986 \\
\hline \multicolumn{4}{|l|}{ Ki67 } \\
\hline$<20 \%$ (low) & 35 & 1.000 & \\
\hline$\geq 20 \%$ (high) & 24 & $0.541(0.266-1.112)$ & 0.094 \\
\hline \multicolumn{4}{|l|}{ Disease type } \\
\hline Primary advanced & 72 & 1.000 & \\
\hline Recurrence & 28 & $0.994(0.556-1.710)$ & 0.984 \\
\hline \multicolumn{4}{|l|}{ Metastatic sites } \\
\hline Visceral & 51 & 1.000 & \\
\hline Non-visceral & 49 & $0.549(0.322-0.924)$ & 0.024 \\
\hline \multicolumn{4}{|l|}{ Organ of metastasis } \\
\hline Liver+others ${ }^{\mathrm{a}}$ & 27 & 1.000 & \\
\hline Bone+regional+lung & 73 & $0.434(0.245-0.801)$ & 0.009 \\
\hline \multicolumn{4}{|l|}{ Prior endocrine therapy } \\
\hline No & 11 & 1.000 & \\
\hline Yes (adjuvant only) & 61 & $1.362(0.398-3.558)$ & 0.584 \\
\hline Yes (recurrence) & 28 & $1.335(0.376-3.733)$ & 0.621 \\
\hline \multicolumn{4}{|c|}{ Line of fulvestrant therapy } \\
\hline 1 & 19 & 1.000 & \\
\hline 2 & 50 & $1.157(0.490-2.435)$ & 0.721 \\
\hline $3+$ & 31 & $0.766(0.316-1.690)$ & 0.520 \\
\hline \multicolumn{4}{|l|}{ Prior chemotherapy } \\
\hline No & 41 & 1.000 & \\
\hline Yes (adjuvant only) & 36 & $0.583(0.315-1.074)$ & 0.083 \\
\hline Yes (recurrence) & 23 & $0.781(0.404-1.532)$ & 0.465 \\
\hline
\end{tabular}

aBrain and intra-abdominal. CI: Confidence intervals; ECOG PS: Eastern Cooperative Oncology Group performance status; FISH: fluorescence in situ hybridization; HER2: human epidermal growth factor receptor 2; IDC: invasive ductal carcinoma; ILC: invasive lobular carcinoma.

requirement necessarily entails some bias, in that the visceral metastases were not imminently life-threatening, the tumour volumes were not especially large, and progression was not rapid; the findings of the analysis reflect these restrictions, and the results must, therefore, be judged accordingly. With these caveats in mind, it is clear that the data from this single-centre Japanese study require additional confirmation before they can be extrapolated to the wider breast cancer population. Nonetheless, they provide important information 
Table III. Univariate analysis of overall survival of patients treated with fulvestrant.

\begin{tabular}{|c|c|c|c|}
\hline Variable & $\begin{array}{c}\text { Number of } \\
\text { patients }\end{array}$ & $\begin{array}{c}\text { Hazard ratio } \\
(95 \% \mathrm{CI})\end{array}$ & $p$-Value \\
\hline \multicolumn{4}{|l|}{ ECOG PS } \\
\hline 0 & 79 & 1.000 & \\
\hline 1 or 2 & 21 & $0.660(0.305-1.586)$ & 0.333 \\
\hline \multicolumn{4}{|l|}{ Histologic type } \\
\hline IDC & 84 & 1.000 & \\
\hline ILC & 5 & $5.925(1.947-14.93)$ & 0.005 \\
\hline \multicolumn{4}{|c|}{ Progesterone receptor status } \\
\hline Positive & 77 & 1.000 & \\
\hline Negative & 17 & $0.519(0.283-1.252)$ & 0.137 \\
\hline \multicolumn{4}{|l|}{ HER2 status by FISH } \\
\hline $3+$ or $2+$ & 5 & 1.000 & \\
\hline $1+$ or 0 & 81 & $0.574(0.118-10.340)$ & 0.618 \\
\hline \multicolumn{4}{|l|}{ Ki67 } \\
\hline$<20$ (low) & 35 & 1.000 & \\
\hline$\geq 20$ (high) & 24 & $3.466(1.225-10.545)$ & 0.019 \\
\hline \multicolumn{4}{|l|}{ Disease type } \\
\hline Primary advanced & 72 & 1.000 & \\
\hline Recurrence & 28 & $1.621(0.752-3.307)$ & 0.209 \\
\hline \multicolumn{4}{|l|}{ Metastatic sites } \\
\hline Visceral & 51 & 1.000 & \\
\hline Non-visceral & 49 & $0.966(0.479-1.946)$ & 0.922 \\
\hline \multicolumn{4}{|l|}{ Organ of metastasis } \\
\hline Liver+others ${ }^{\mathrm{a}}$ & 27 & 1.000 & \\
\hline Bone+regional+lung & 73 & $0.863(0.412-1.972)$ & 0.711 \\
\hline \multicolumn{4}{|l|}{ Prior endocrine therapy } \\
\hline No & 11 & 1.000 & \\
\hline Yes (adjuvant) & 61 & $1.009(0.290-6.362)$ & 0.991 \\
\hline Yes (recurrence) & 28 & $1.634(0.433-10.626)$ & 0.503 \\
\hline \multicolumn{4}{|c|}{ Line of fulvestrant therapy } \\
\hline 1 & 19 & 1.000 & \\
\hline 2 & 50 & $0.786(0.294-2.463)$ & 0.655 \\
\hline $3+$ & 31 & $1.102(0.421-3.417)$ & 0.851 \\
\hline \multicolumn{4}{|l|}{ Prior chemotherapy } \\
\hline No & 41 & 1.000 & \\
\hline Yes (adjuvant) & 36 & $1.346(0.576-3.282)$ & 0.494 \\
\hline Yes (recurrence) & 23 & $2.026(0.816-5.101)$ & 0.126 \\
\hline
\end{tabular}

aBrain and intra-abdominal. CI: Confidence intervals; ECOG PS: Eastern Cooperative Oncology Group performance status; FISH: fluorescence in situ hybridization; HER2: human epidermal growth factor receptor 2; IDC: invasive ductal carcinoma; ILC: invasive lobular carcinoma.

for discussion by the clinical community and may provide some guidance to clinicians deciding on the optimal treatment sequence for their patients with advanced or metastatic breast cancer.

In conclusion, in this analysis of patients with metastatic breast cancer who were found to be eligible for hormone therapy and received fulvestrant in clinical practice, patients with non-visceral metastases had a better prognosis than those with visceral metastases. Of patients with visceral metastases, those with lung metastasis had a good prognosis comparable with that of patients with non-visceral metastases. There was no difference in prognosis among treatment lines, and no problems with tolerability were detected. We anticipate that these data will be useful when deciding whether to use fulvestrant alone or in combination with a CDK4/6 inhibitor.

\section{Conflicts of Interest}

YaM has received lecture fees or grants from Chugai Pharmaceutical, AstraZeneca, Eli Lilly, Pfizer, Eisai, MSD, and Taiho Pharmaceutical. All other authors declare that they have no conflicts of interest.

\section{Acknowledgements}

This study was funded by the Hyogo College of Medicine (no grant number was provided). We thank Sally-Anne Mitchell, $\mathrm{PhD}$, of Edanz Medical Writing, for providing medical writing support, which was funded by AstraZeneca.

\section{Authors' Contributions}

$\mathrm{HO}$ and MI contributed to data acquisition and analysis, and to drafting, critically revising and approving the final version of the manuscript. AS, RF, AB, TH, YF, and YoM each contributed to data acquisition, and to critically revising and approving the final version of the manuscript. YaM conceived and designed the study, interpreted the data, and contributed to drafting, critically revising and approving the final version of the manuscript. All Authors take responsibility for the accuracy and integrity of the manuscript and data.

\section{References}

1 NCCN Clinical Practice Guidelines in Oncology: Breast Cancer. Version 1. 2019. National Comprehensive Cancer Network, 2019. Available at: https://www.nccn.org/professionals/physician_gls/ pdf/breast.pdf. Last accessed on 23rd July 2019.

2 Nathan MR and Schmid P: A review of fulvestrant in breast cancer. Oncol Ther 5(1): 17-29, 2017. PMID: 28680952. DOI: 10.1007/s40487-017-0046-2

3 Deeks ED: Fulvestrant: A review in advanced breast cancer not previously treated with endocrine therapy. Drugs 78(1): 131-137, 2018. PMID: 29270913. DOI: 10.1007/s40265-017-0855-5

4 Faslodex $^{\circledR}$ (fulvestrant) prescribing information. AstraZeneca Pharmaceuticals LP, Wilmington, DE 19850, USA; August 2017. Available at: https://www.accessdata.fda.gov/drugsatfda_docs/label/ 2017/021344s034lbl.pdf. Last accessed on 23rd July 2019.

5 Robertson JFR, Bondarenko IM, Trishkina E, Dvorkin M, Panasci L, Manikhas A, Shparyk Y, Cardona-Huerta S, Cheung KL, Philco-Salas MJ, Ruiz-Borrego M, Shao Z, Noguchi S, Rowbottom J, Stuart M, Grinsted LM, Fazal M and Ellis MJ: Fulvestrant $500 \mathrm{mg}$ versus anastrozole $1 \mathrm{mg}$ for hormone receptor-positive advanced breast cancer (FALCON): an international, randomised, double-blind, phase 3 trial. Lancet 388(10063): 2997-3005, 2016. PMID: 27908454. DOI: 10.1016/S0140-6736(16)32389-3

6 Robertson JF, Llombart-Cussac A, Rolski J, Feltl D, Dewar J, Macpherson E, Lindemann $\mathrm{J}$ and Ellis MJ: Activity of 
fulvestrant $500 \mathrm{mg}$ versus anastrozole $1 \mathrm{mg}$ as first-line treatment for advanced breast cancer: results from the FIRST study. J Clin Oncol 27(27): 4530-4535, 2009. PMID: 19704066. DOI: $10.1200 / \mathrm{JCO} .2008 .21 .1136$

7 Ellis MJ, Llombart-Cussac A, Feltl D, Dewar JA, Jasiówka M, Hewson N, Rukazenkov Y and Robertson JF: Fulvestrant 500 $\mathrm{mg}$ versus anastrozole $1 \mathrm{mg}$ for the first-line treatment of advanced breast cancer: overall survival analysis from the phase II FIRST study. J Clin Oncol 33(32): 3781-3787, 2015. PMID: 26371134. DOI: $10.1200 / \mathrm{JCO} .2015 .61 .5831$

8 Di Leo A, Jerusalem G, Petruzelka L, Torres R, Bondarenko IN, Khasanov R, Verhoeven D, Pedrini JL, Smirnova I, Lichinitser MR, Pendergrass K, Garnett S, Lindemann JP, Sapunar F and Martin M: Results of the CONFIRM phase III trial comparing fulvestrant $250 \mathrm{mg}$ with fulvestrant $500 \mathrm{mg}$ in postmenopausal women with estrogen receptor-positive advanced breast cancer. J Clin Oncol 28(30): 4594-4600, 2010. PMID: 20855825. DOI: 10.1200/JCO.2010.28.8415

9 Finn RS, Crown JP, Lang I, Boer K, Bondarenko IM, Kulyk SO, Ettl J, Patel R, Pinter T, Schmidt M, Shparyk Y, Thummala AR, Voytko NL, Fowst C, Huang X, Kim ST, Randolph S and Slamon DJ: The cyclin-dependent kinase $4 / 6$ inhibitor palbociclib in combination with letrozole versus letrozole alone as first-line treatment of oestrogen receptor-positive, HER2negative, advanced breast cancer (PALOMA-1/TRIO-18): A randomised phase 2 study. Lancet Oncol 16(1): 25-35, 2015. PMID: 25524798. DOI: 10.1016/S1470-2045(14)71159-3

10 Hortobagyi GN, Stemmer SM, Burris HA, Yap YS, Sonke GS, Paluch-Shimon S, Campone M, Blackwell KL, André F, Winer EP, Janni W, Verma S, Conte P, Arteaga CL, Cameron DA, Petrakova K, Hart LL, Villanueva C, Chan A, Jakobsen E, Nusch A, Burdaeva O, Grischke EM, Alba E, Wist E, Marschner N, Favret AM, Yardley D, Bachelot T, Tseng LM, Blau S, Xuan F, Souami F, Miller M, Germa C, Hirawat S and O'Shaughnessy J: Ribociclib as first-line therapy for HR-positive, advanced breast cancer. N Engl J Med 375(18): 1738-1748, 2016. PMID: 27717303. DOI: 10.1056/NEJMoa1609709

11 Dickler MN, Tolaney SM, Rugo HS, Cortés J, Diéras V, Patt D, Wildiers H, Hudis CA, O'Shaughnessy J, Zamora E, Yardley DA, Frenzel M, Koustenis A and Baselga $\mathrm{J}$ : MONARCH 1, a phase II study of abemaciclib, a CDK4 and CDK6 inhibitor, as a single agent, in patients with refractory HR+/HER2- metastatic breast cancer. Clin Cancer Res 23(17): 5218-5224, 2017. PMID: 28533223. DOI: 10.1158/10780432.CCR-17-0754

12 Sledge GW Jr, Toi M, Neven P, Sohn J, Inoue K, Pivot X, Burdaeva O, Okera M, Masuda N, Kaufman PA, Koh H, Grischke EM, Frenzel M, Lin Y, Barriga S, Smith IC, Bourayou $\mathrm{N}$ and Llombart-Cussac A: MONARCH 2: Abemaciclib in combination with fulvestrant in women with HR+/HER2advanced breast cancer who had progressed while receiving endocrine therapy. J Clin Oncol 35(25): 2875-2884, 2017. PMID: 28580882. DOI: 10.1200/JCO.2017.73.7585

13 Sobhani N, D’Angelo A, Pittacolo M, Roviello G, Miccoli A, Corona SP, Bernocchi O, Generali D and Otto T: Updates on the CDK4/6 inhibitory strategy and combinations in breast cancer. Cells 8(4): E321, 2019. PMID: 30959874. DOI: 10.3390/cells 8040321

14 Eggersmann TK, Degenhardt T, Gluz O, Wuerstlein R and Harbeck N: CDK4/6 inhibitors expand the therapeutic options in breast cancer: palbociclib, ribociclib and abemaciclib. BioDrugs 33(2): 125-135, 2019. PMID: 30847853. DOI: 10.1007/s40259-019-00337-6

15 Ibrance $^{\circledR}$ (palbociclib) prescribing information. Pfizer Inc., NY, NY 10017, USA; March 2017. Available at: https:// www.accessdata.fda.gov/drugsatfda_docs/label/2017/207103s00 4lbl.pdf. Last accessed on 23rd July 2019.

$16 \mathrm{Kisqali}^{\circledR} \quad$ (ribociclib) prescribing information. Novartis Pharmaceuticals Corp., East Hanover, NJ 07936, USA; July 2018. Available at: https://www.pharma.us.novartis.com/sites/ www.pharma.us.novartis.com/files/kisqali.pdf. Last accessed on 23rd July 2019.

17 Verzenio $^{\circledR}$ (abemaciclib) prescribing information. Lilly USA LLC, Indianapolis, IN 46284, USA; September 2017. Available at: https://www.accessdata.fda.gov/drugsatfda_docs/label/ 2017/208716s000lbl.pdf. Last accessed on 23rd July 2019.

18 Spring LM, Wander SA, Zangardi M and Bardia A: CDK 4/6 inhibitors in breast cancer: Current controversies and future directions. Curr Oncol Rep 21(3): 25, 2019. PMID: 30806829. DOI: $10.1007 / \mathrm{s} 11912-019-0769-3$

19 Xi J, Oza A, Thomas S, Ademuyiwa F, Weilbaecher K, Suresh R, Bose R, Cherian M, Hernandez-Aya L, Frith A, Peterson L, Luo J, Krishnamurthy J and Ma CX: Retrospective analysis of treatment patterns and effectiveness of palbociclib and subsequent regimens in metastatic breast cancer. J Natl Compr Canc Netw 17(2): 141-147, 2019. PMID: 30787127. DOI: $10.6004 /$ jncen.2018.7094

20 Chen W, Hoffmann AD, Liu H and Liu X: Organotropism: new insights into molecular mechanisms of breast cancer metastasis. NPJ Precis Oncol 2(1): 4, 2018. PMID: 29872722. DOI: 10.1038/s41698-018-0047-0

21 Ma R, Feng Y, Lin S, Chen J, Lin H, Liang X, Zheng H and Cai $\mathrm{X}$ : Mechanisms involved in breast cancer liver metastasis. J Transl Med 13: 64, 2015. PMID: 25885919. DOI: 10.1186/ s12967-015-0425-0

22 Obenauf AC and Massagué J: Surviving at a distance: Organ specific metastasis. Trends Cancer 1(1): 76-91, 2015. PMID: 26693180. DOI: 10.1016/j.trecan.2015.07.009

23 Ge QD, Lv N, Kong YN, Xie XH, He N, Xie XM and Wei WD: Clinical characteristics and survival analysis of breast cancer molecular subtypes with hepatic metastases. Asian Pac J Cancer Prev 13(10): 5081-5086, 2012. PMID: 23244114. DOI: 10.7314/apjcp.2012.13.10.5081

24 Faslodex ${ }^{\circledR}$ (fulvestrant) Japanese package insert. AstraZeneca K.K., Osaka, Japan; September 2017. Available at: http:// www.info.pmda.go.jp/go/pack/4291421G1020_1_07/). Last accessed on 23rd July 2019.

25 Newton PK, Mason J, Venkatappa N, Jochelson MS, Hurt B, Nieva J, Comen E, Norton L and Kuhn P: Spatiotemporal progression of metastatic breast cancer: a Markov chain model highlighting the role of early metastatic sites. NPJ Breast Cancer 1: 15018, 2015. PMID: 28721371. DOI: 10.1038/npjbcancer. 2015.18

26 Dupuy F, Tabariès S, Andrzejewski S, Dong Z, Blagih J, Annis MG, Omeroglu A, Gao D, Leung S, Amir E, Clemons M, Aguilar-Mahecha A, Basik M, Vincent EE, St-Pierre J, Jones RG and Siegel PM: PDK1-dependent metabolic reprogramming dictates metastatic potential in breast cancer. Cell Metab 22(4): 577-589, 2015. PMID: 26365179. DOI: 10.1016/j.cmet.2015.08 .007 
27 Di Leo A, Jerusalem G, Petruzelka L, Torres R, Bondarenko IN, Khasanov R, Verhoeven D, Pedrini JL, Smirnova I, Lichinitser MR, Pendergrass K, Malorni L, Garnett S, Rukazenkov $\mathrm{Y}$ and Martin M: Final overall survival: fulvestrant $500 \mathrm{mg}$ vs $250 \mathrm{mg}$ in the randomized CONFIRM trial. J Natl Cancer Inst 106(1): djt337, 2014. PMID: 24317176. DOI: 10.1093/jnci/djt337

28 Robertson JF, Lindemann JP, Llombart-Cussac A, Rolski J, Feltl D, Dewar J, Emerson L, Dean A and Ellis MJ: Fulvestrant $500 \mathrm{mg}$ versus anastrozole $1 \mathrm{mg}$ for the first-line treatment of advanced breast cancer: follow-up analysis from the randomized 'FIRST' study. Breast Cancer Res Treat 136(2): 503-511, 2012. PMID: 23065000. DOI: 10.1007/s10549-0122192-4
29 Pizzuti L, Natoli C, Gamucci T, Mauri M, Sergi D, Di Lauro L, Paoletti G, Ruggeri E, Iezzi L, Sperduti I, Mentuccia L, Fabbri A, Maugeri-Saccà M, Moscetti L, Barba $\mathrm{M}$ and Vici $\mathrm{P}$ : Anthropometric, clinical and molecular determinants of treatment outcomes in postmenopausal, hormone receptor positive metastatic breast cancer patients treated with fulvestrant: Results from a real word setting. Oncotarget 8(40): 69025-69037, 2017. PMID: 28978178. DOI: $10.18632 /$ oncotarget.16982

Received August 1, 2019 Revised August 21, 2019 Accepted August 22, 2019 